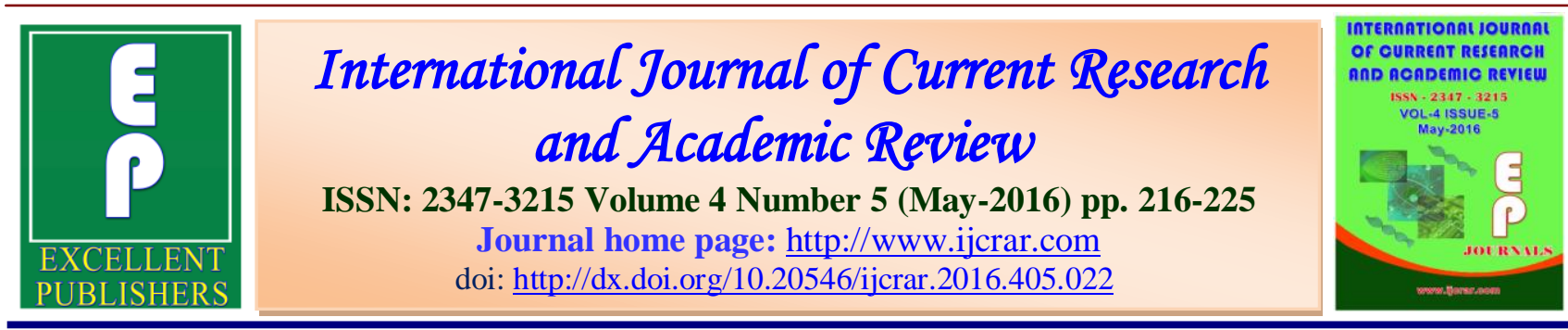

\title{
Evaluation of response to treatment with Ribavirin plus Peginterferon in patients with chronic hepatitis $\mathrm{C}$ genotype $\mathbf{1 b}$
}

\author{
Abolfazl Pourhasan ${ }^{1}$ and Neda Zamen Milani ${ }^{2 *}$ \\ ${ }^{1}$ Infectious and Tropical Diseases Research center, Tabriz University of Medical Sciences, \\ Tabriz, Iran \\ ${ }^{2}$ Department of Infectious Diseases, Faculty of Medicine, Tabriz University of Medical \\ Sciences, Tabriz, Iran \\ *Corresponding author
}

\begin{tabular}{|c|c|}
\hline KEYWORDS & $A B S T R A C T$ \\
\hline $\begin{array}{l}\text { Hepatitis C, } \\
\text { Ribavirin, } \\
\text { Peginterferon, } \\
\text { Response to } \\
\text { treatment }\end{array}$ & $\begin{array}{l}\text { Chronic infection with hepatitis } \mathrm{C} \text { virus is a global health problem that can lead to } \\
\text { cirrhosis, hepatic disease and hepatic cancer. One of the standard treatments for } \\
\text { hepatitis } \mathrm{C} \text { genotype } 1 \mathrm{~b} \text { is Peginterferon plus Ribavirin for } 48 \text { weeks that has } \\
\text { different response to treatment. Response to treatment could be influenced by } \\
\text { different factors. In this study we aim to evaluate the factors related to response to } \\
\text { treatment and the rate of response to treatment with Ribavirin plus Peginterferon in } \\
\text { patients with chronic hepatitis } \mathrm{C} \text { genotype } 1 \mathrm{~b} \text {. In this analytical cross-sectional study, } \\
90 \text { patients including } 44 \text { male and } 46 \text { female with mean age of } 38.01 \pm 11.10 \text { years } \\
\text { with the definite diagnosis of Hepatitis } \mathrm{C} \text { who were treated with Ribavirin plus } \\
\text { Peginterferon were included and followed for } 48 \text { weeks. In all patients demographic } \\
\text { findings, underlying disease and social habits were recorded. Response to treatment } \\
\text { was defined at weeks } 12,24 \text { and } 48 \text { and different factors were evaluated between } \\
\text { groups. Response to treatment was observed in } 68 \text { cases }(75.6 \%) \text {, recurrence in } 16 \\
\text { cases }(16.7 \%) \text { and treatment cessation in } 7 \text { cases }(7.7 \%) \text {. Opium was used in } 1.1 \% \text {, } \\
\text { alcohol in } 7.8 \% \text { and smoking in } 22.2 \% \text {. Also, hepatitis B in } 2.2 \% \text { and diabetes in } \\
6.7 \% \text { were observed. There were no significant differences between cases with and } \\
\text { without response to treatment regarding age, gender, weight, alcohol use, smoking or } \\
\text { diabetes. Results of current study showed that treatment with Ribavirin plus } \\
\text { Peginterferon in patients with chronic hepatitis C genotype } 1 \mathrm{~b} \text { unlike previous studies } \\
\text { accompanies with higher response to treatment ( } 75.6 \%) \text { and different factors have no } \\
\text { significant influence in the response to treatment. }\end{array}$ \\
\hline
\end{tabular}

\section{Introduction}

Chronic infection with $\mathrm{HCV}$ is a global health problem that can lead to cirrhosis of the liver and liver cancer (1). Cirrhosis of the liver caused by $\mathrm{HCV}$ is the most common indication for liver transplantation and is a major factor contributing in the increasing incidence of HCC. One hundred and thirty to 150 million people worldwide are chronically infected and 300-500 thousand people annually die due to the 
infection of hepatitis C (3-2). Successful treatment of $\mathrm{HCV}$ is associated with achieving SVR (4-5). Patients reaching the SVR can enjoy long-term benefits associated with improved fibrosis, reduced complications of chronic liver disease, and improved quality of life (6).

One of the standard treatments for hepatitis C genotype 1 is performed with a combination of Interferon $\alpha-2 b$ and Ribavirin and $48-41 \%$ of patients under treatment reached SVR and it seems that it is lasting for a long period and is associated with long-term benefits ( 8 and 7 ). It is shown that the combination of Peginterferon and Ribavirin has improves this response rate up to $54 \%$. Furthermore, a retrospective study showed a $61 \%$ response when Peginterferon and Ribavirin doses are assessed based on the patient's weight. Treatment by the combination of interferon $\alpha$-2bor Peginterferon $\alpha 2 b$ and Ribavirin requires a balanced treatment regimen including subcutaneous injection, oral prescription twice a day, frequent visits along with blood tests to assess the health and side effects in almost all patients (9).

In patients with genotype 2 and 3, 24-week treatment with $180 \mathrm{~g} / \mathrm{w}$ Peginterferon in combination with $800 \mathrm{mg} /$ day Ribavirin resulted in SVR in approximately $80 \%$ of patients. It has not proven that higher doses of Ribavirin and prolonged treatment improve the response of the patient. However, in positive-HCV patients with the genotype $1 b$, higher doses of Ribavirin 1000-2000 mg / day and 48-week treatment period to reach at least $50 \% \mathrm{SVR}$ are necessary (10). Therefore, treatment of patients with HCV genotype 1 seems difficult and a stronger regimen is recommended to achieve maximum virologic response (11). In most treatment regimens, successful treatment is associated with more contact with medicine. Being exposed to a drug depends on the drug's pharmacokinetic properties and the patient's capability to tolerate the extent to the treatment regimen in which the drug is prescribed for a particular period (11).

Recently, new drugs and different regimes have been introduced for the treatment of hepatitis C. New drugs contain combinations of Sofosbuvir and Ledipasvir, Simeprevir, Daclatasvir, Ritonavir, Paritaprevir and Ombitasvir and Dasabuvir combination. However, due to the high cost and lack of access to new drugs, Peginterferon and Ribavirin standard regimen is often used (12). According to what mentioned, this study aimed to investigate the factors influencing the response to treatment and the amount of response to interferon and Ribavirin treatment in patients with hepatitis C.

\section{Materials and Methods}

In a cross-sectional study conducted in Tabriz on patients with hepatitis $\mathrm{C}$, the response to the combination of Ribavirin and Peginterferon treatment in patients with genotype $1 b$ hepatitis $\mathrm{C}$ was evaluated. In this study, all patients who were diagnosed with hepatitis C during the 2014s and referred to the infectious disease clinics for treatment were included and treated by Ribavirin and Peginterferon. In this period, 120 patients were evaluated.

\section{Exclusion criteria}

1. Patients with genotypes other than $1 b$.

2. Patients with no further reference and their evaluation remained incomplete.

3. Patients with discontinued treatment due to lack of response to the treatment.

4. Patients who regressed by this treatment regimen and their treatment was replaced by Pegasys. 
All patients enrolled in the study were first evaluated using a checklist.

Underlying diseases including hepatitis B, AIDS, and diabetes were considered. Participants were also asked about their smoking habit, alcohol drinking, and drug injection. HCVRNA, AIT, AST were evaluated at baseline, three months and six months after treatment and at the end of the treatment. PCR was analyzes through sending samples to the Keyvan Virology Laboratory in Tehran and using the COBAS-TaqMan.48 Analyzer and RocheApplied-Science kits made in Germany.

\section{Ethical Considerations}

Written consent was collected from all patients before the study. No additional costs were imposed on patients and all the required tests were provided by the approved project. Patients' names and addresses are mentioned nowhere and their information remained confidential. Moreover, biopsy of the liver was not performed because of its potential risks.

\section{Statistical Analysis}

The collected data were analyzed by SPSS17 statistical software. The collected data were expressed as percentage and mean \pm SD. Continuous (quantitative) variables were compared by Independent samples and Paired $t$ test. Categorical (qualitative) variables were compared by contingency tables and Chi-square test or Fisher's exact test. P-value $\leq 0.05$ was considered statistically significant.

\section{Results and Discussion}

In the present study, 20 out of 120 studied patients were suffering from genotype other than $1 b$ who were excluded from the study. Ten patients had no further reference and their examination remained incomplete. Finally, the study continued with 90 patients. Of 120 patients, 15 cases regressed by this treatment regimen and their treatment was replaced by Pegasys and 7 cases discontinued treatment due to lack of response to the treatment and 68 cases responded to this treatment. The response to the treatment was 75.6 percent.

Forty-four cases $(48.9 \%)$ were males and 46 $(51.1 \%)$ were female. The mean age of patients was equal to $11.10 \pm 38.01$ years. Patients' weight mean was $14.15 \pm 73.32 \mathrm{~kg}$. There were also observed opium consumption in one case $(1.1 \%)$, alcohol drinking in 7 cases $(7.8 \%)$ and smoking in 20 cases $(22.2 \%)$.

There were Hepatitis B in 2 cases $(2.2 \%)$ and diabetes in 6 cases $(6.7 \%)$. At the treatment week 12 , respond to treatment was observed in all patients.

At the treatment week 24, there was treatment discontinuation for 4 patients $(4.4 \%)$ and disease recurrence in 9 patients $(10 \%)$ with changed treatment. At the treatment week 48, among the remained 77 patients, there was treatment discontinuation for 3 patients $(3.9 \%)$ and disease recurrence in 6 patients $(7.8 \%)$ with changed treatment. The average age of patients responsive to the treatment was $11.73 \pm 37.73$ years and the average age of patients unresponsive to the treatment was $9.08 \pm 38.86$ years. Despite the lower age of patients responsive to the treatment, the difference between two groups was not statistically significant $(\mathrm{P}=0.68)$. The average weights of patients responsive to the treatment and patients unresponsive to the treatment were $14.50 \pm$ 72.91 and $13.35 \pm 74.59 \mathrm{~kg}$, respectively. In this case, despite the lower weight of patients responsive to the treatment, the difference between two groups was not statistically significant $\quad(\mathrm{P}=0.63)$. Both 
patients with hepatitis $B$ and the patient with the habit of taking opium had responded to treatment.

Figure 3-4 shows the frequency rate of alcohol drinking among cases responsive and unresponsive to the treatment. As it can be observed in this figure, patients responsive to the treatment had lower levels of alcohol consumption than those unresponsive to the treatment; however, the difference was not statistically significant $(\mathrm{P}=0.23)$.

Figure 4-4 shows the frequency rate of smoking among cases responsive and unresponsive to the treatment. As it can be observed in this figure, patients responsive to the treatment had higher smoking frequency than those unresponsive to the treatment; however, the difference was not statistically significant $(\mathrm{P}=0.6)$.

In this study, there were diabetes in 4 patients with therapeutic response $(5.9 \%)$ and 2 patients unresponsive to the treatment $(9.1 \%)$. Despite the higher frequency of diabetes in patients unresponsive to the treatment, the difference between two groups was not statistically significant $(\mathrm{P}=0.63)$.

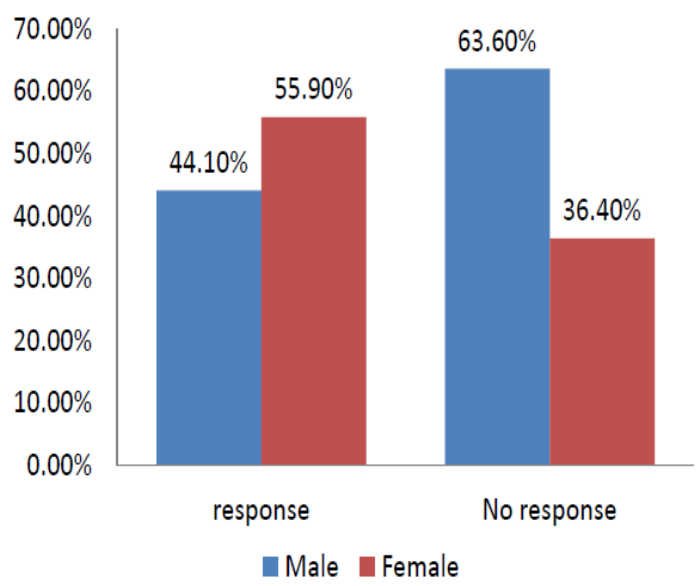

Chart.1 Frequency of patient's gender between response and no response groups

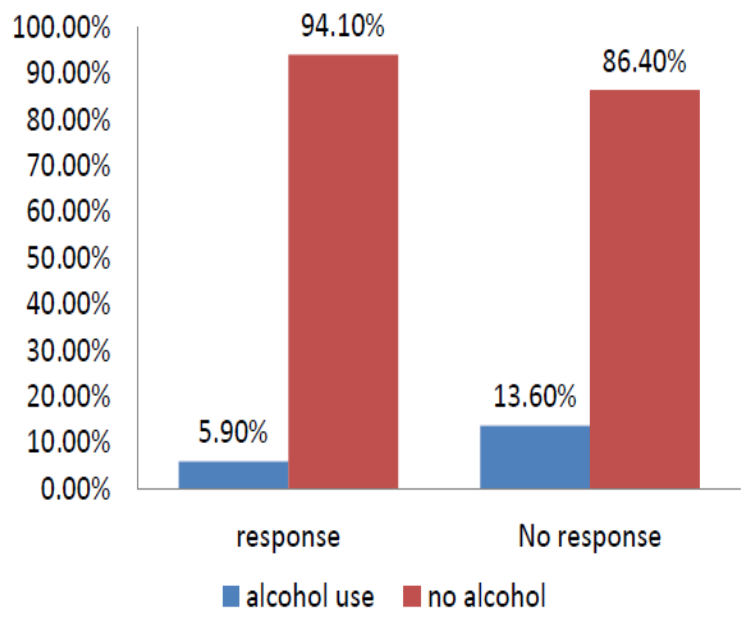

Chart.2 Frequency of alcohol usage between response and no response groups 


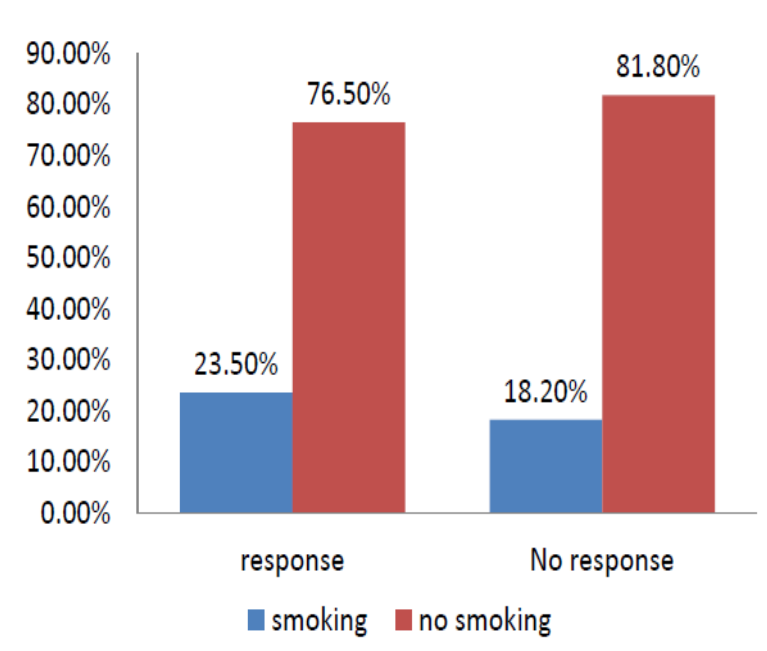

Chart.3 Frequency of Cigarette usage between response and no response groups

The primary goal of hepatitis $\mathrm{C}$ treatment is improving infection. A sustained virologic response (SVR) is determined by undetectable HCV RNA at week 12 or week 24 after treatment completion. Infections are improved in more than $99 \%$ of patients who reach SVR. SVR in patients without cirrhosis is generally associated with improved liver disease. Patients with cirrhosis are at risk of life-threatening complications. However, liver fibrosis may progress by SVR and the risk of complications such as liver failure and hypertension ports may decrease (25 and 24).

Until 2011, the combination of Peginterferon Alpha and Ribavirin was approved for 24 or 48 weeks of treatment in chronic hepatitis $C$ (26). With this regimen in patients with hepatitis $\mathrm{C}$ genotype $1, \mathrm{SVR}$ rate reached $40 \%$ in North America and $50 \%$ in West Europe. Higher SVR rates were reached in patients with hepatitis 2,3 , 5 and 6. The average rate of SVR was achieved in patients with genotype 4 hepatitis C (27).

In 2011, Telaprevir and Boceprevir were approved to be used for Hepatitis C genotype 1 . These two medicines are a part of the first generation of DAA drugs. Both drugs must be prescribed in combination with Peginterferon Alpha and Ribavirin. In phase III of Telaprevir and Boceprevir trial, among patients with Hepatitis $\mathrm{C}$ genotype 1 with no pre-treatment, three-drug treatment regimen compared to two-drug regimen with Ribavirin and Peginterferon achieved higher SVR. However, three-drug treatment regimen had greater side effects and costs (31-28).

In 2014, three new DAA drugs were confirmed to be used as a part of combination therapy for hepatitis C infection. Sofosbuvir, Simeprevir, and Daclatasvir were confirmed in January 2014, May 2014, and August 2014, respectively.

Each of these drugs can be used as a part of a three-drug combination regimen with Peginterferon Alpha and Ribavirin. Regarding the used drug, the genotype of hepatitis $\mathrm{C}$, drug resistance, and liver disease severity, SVR will vary from $40 \%$ to $100 \%$ (12).

With the arrival of these three new drugs, interferon-free treatment regimens have been widely used in Europe since 2014. The combination of Ribavirin and Sofosbuvir in patients with hepatitis C genotypes 2 (12 
weeks) or genotype 3 (14 weeks) resulted in $80-95 \%$ SVR. The combination of Simeprevir and Sofosbuvir in patients with hepatitis C genotypes 1 resulted in 93-100\% SVR. The combination of Sofosbuvir and Simeprevir with or without Ribavirin in patients with hepatitis $\mathrm{C}$, genotype 1 resulted in 93-100\% SVR (1). The combination of Sofosbuvir and Daclatasvir with or without Ribavirin is widely used in Europe for patients with advanced liver disease. It resulted in 95-100\% SVR in patients with hepatitis $C$ genotype 1(32).

Existing drugs consist of Peginterferon Alpha, Ribavirin, Sofosbuvir, Sofosbuvir and Ledipasvir combination, Simeprevir, Daclatasvir, Ritonavir, Paritaprevir and Ombitasvir and Dasabuvir combination.

Six treatment regimens for patients with hepatitis $\mathrm{C}$ genotype 1 were suggested in 2015 (12). These show that new drugs would lead to achieving an ideal high SVR. However, some differences in the economy and health care system of communities make the treatment by Ribavirin and Peginterferon regimens continue without new drugs.

In the present study, due to the unavailability of these drugs, treatment responses to Ribavirin and Peginterferon were assessed. In the present study, we evaluated the treatment response to Interferon and Ribavirin in patients with hepatitis $\mathrm{C}$ genotype 1 and its affecting factors. It was observed that more than three-quarters of patients $(75.6 \%)$ responded appropriately to treatment at the end of 48 weeks.

Unlike the current study, the treatment response was reported up to $60 \%$ in previous studies. In a research study, Vadim et al. found that the SVR in Genotype $1 b 1$ was $46.1 \%$ (19). In another study conducted by
Zeuzem et al., SVR was 50\% (21). In Urbanek's study, the observed treatment response in genotype $1 b$ was equal to $55 \%$ (33).

However, there was only one study with results similar to the results of the present study. Ma et al. in their study observed that the response at the end of 48 weeks of treatment by Peginterferon and Ribavirin in genotype 1 was $73.6 \%$ (34).

In different studies, different factors have been considered involved in the response to a treatment. The main factors effective in the antiviral treatment of Hepatitis $\mathrm{C}$ can be divided into two major categories: Factors related to the virus including virus genotype, baseline virology, virologic response during treatment, and host factors such as age, sex, race, obesity, alcohol consumption, and the degree of liver fibrosis (16).

In the present study it was observed that cases responsive to the treatment, compared unresponsive cases, had lower mean age and weight, were mainly females, consumed less alcohol and smoked more, and suffered from diabetes to a lesser extent. However, there was no significant statistical difference between two groups.

Javier et al. observed that older age is associated with a lower rate of response to treatment (18). Vadim et al. also concluded that the SVR rate in patients younger than 40 years old, compared to older people, is higher (19). Zeuzem et al. in their study found that, some predictive factors including age, base HCV-RNA and the duration of treatment were significantly associated with SVR; however, it has no significant relationship with gender, race, weight, source of exposure, duration of exposure, the dose of Ribavirin, Metavir and Knodell scores (21). Berg et al. also reported that, in 
the 48-week treatment, there is no significant relationship between race, gender, height, fibrosis, and ALT and the treatment results. However, age, weight, blood glucose level, and HCV-RNA had significant correlation with those results (22).

Depending on the sample size of patients and patients' specifications, different studies have suggested various factors in the response to the treatment. However, none of these factors had a significant role in this study. This treatment should be considered for all patients with chronic liver disease associated with hepatitis $\mathrm{C}$, who have not been treated so far or have already experienced treatment and have no contraindication for treatment.

Prior to the treatment, other causes chronic liver disease or factors affecting the progression of liver disease should be assessed and all patients should be checked for other hepatotoxic viruses, particularly hepatitis B and immunodeficiency viruses. Alcohol consumption should be assessed and its discontinuation shall be recommended. Possible comorbidities including autoimmune disease, metabolic or genetic liver diseases (eg, hemochromatosis, diabetes, obesity) and drug hepatotoxicity should be assessed (12).

Prior to the treatment, assessing the severity of the liver disease with regard to cirrhosis or advanced fibrosis is also important. Evaluation of fibrosis in patients with clinical evidence of cirrhosis is not necessary and these patients do need to be evaluated in terms of hepatocellular carcinoma. Over many years, liver biopsy has been an acceptable method for determining the phase of histologic progress and disease activity. Liver stiffness measurement contributes in the estimation of liver fibrosis in patients with hepatitis C.
Biomarkers representing fibrosis can also be used. Using the combination of these methods reduce the need for the liver biopsy. It would also be useful for patients with coagulation disorders (36 and 35).

Quantifying RNA HCV in patients under treatment has indications and shall be carried out a reliable and sensitive method and expressed in IU/mL. HCV genotype and the subtype of genotype 1 should be determined prior to treatment. Determining genotype and subtype must be done by a method which would accurately distinguish between subtypes $1 a$ and $1 b$ (37).

Test of resistance to first-line drugs is not required since resistance has no high impact on treatment and the outcome of the treatment, except for patients infected with subtype $1 a$ who were treated by Peginterferon Alpha, Ribavirin and Simeprevir (12).

Cirrhotic patients achieving SVR should be examined by ultrasonography for HCC every 6 months and by endoscopy for esophageal varices, if they were with esophageal varices prior to the treatment. Non-cirrhotic patients achieving SVR shall be evaluated for HCV RNA during the week 48 after treatment and if the HCV RNA is still not recognized, infection can be considered cured. There is no need to recheck HCV-RNA (25 and 24).

Despite what mentioned, following points are important in making decision:

Treatment of chronic hepatitis $\mathrm{C}$ is contraindicated by the regimens containing Peginterferon Alpha and Ribavirin in uncontrolled depression, psychosis, convulsion of pregnant women or couples who do not use safe contraceptive methods, severe simultaneous, diseases, comorbidities including retinal disease, thyroid disease, 
autoimmune disease, and decompensated liver disease. The use of Peginterferon Alpha in patients with neutrophils less than 1500 or platelets less than/ equal to 90,000 is not recommended. Sofosbuvir in patients with severe renal insufficiency should be used with caution. The combination of Ritonavir, Paritaprevir, Ombitasvir and Dasabuvir in patients with decompensated cirrhosis Child-Pugh-C is contraindicated (12).

Peginterferon Alpha and Ribavirin side effects include neutropenia, anemia, thrombocytopenia, and lymphopenia. These parameters shall be checked in weeks 1,2 and 4 of therapy and then in each 4-8 weeks (12).

\section{Conclusion}

Results of this study showed that, unlike previous studies, treatment using the combination of Ribavirin and Peginterferon therapy in the treatment of patients with hepatitis $\mathrm{C}$ genotype $1 \mathrm{~b}$ is associated with greater rate of response to the treatment $(75.6 \%)$ and various factors have no significant impact on the treatment response.

\section{Recommendations}

According to the results of this study, using the combination of Ribavirin and Peginterferon therapy in the treatment of patients with hepatitis C genotype $1 \mathrm{~b}$ is recommended. However, further studies with larger sample sizes can provide more accurate results in this regard.

\section{References}

1.Lawitz E, Sulkowski MS, Ghalib R, Rodriguez-Torres M, Younossi ZM, Corregidor A, et al. (2014) Simeprevir plus sofosbuvir, with or without ribavirin, to treat chronic infection with hepatitis $\mathrm{C}$ virus genotype 1 in nonresponders to pegylated interferon and ribavirin and treatment-naive patients: the COSMOS randomised study. Lancet, 384, 1756-65.

2.Verna EC, Brown RS. (2006) Hepatitis C virus and liver transplantation. Clin Liver Dis, 10, 919-40.

3.Lauer GM, Walker BD. (2001) Hepatitis C virus infection. $N$ Engl J Med, 345, 4152.

4.McHutchison JG, Lawitz EJ, Shiffman ML, Muir AJ, Galler GW, McCone J, et al. (2009) Peginterferon ab or alfa-2a with ribavirin for treatment of hepatitis $\mathrm{C}$ infection. $N$ Engl J Med, 361, 580-93.

5.Fried MW, Shiff man ML, Reddy KR, Smith C, Marinos G, Gonçales FL Jr, et al. (2002) Peginterferon alfa-2a plus ribavirin for chronic hepatitis $\mathrm{C}$ virus infection. $N$ Engl J Med, 347, 975-82.

6.Kwo PY, Lawitz EJ, McCone J, Schiff ER, Vierling JM, Pound D, et al. (2010) Efficacy of boceprevir, an NS3 protease inhibitor, in combination with Peginterferon alfa-2b and ribavirin in treatment-naive patients with genotype 1 hepatitis C infection (SPRINT-1): an open-label, randomised, multicentre phase 2 trial. Lancet, 376, 705-716.

7.McHutchison JG, Gordon SC, Schiff ER, Shiffman ML, Lee WL, Rustgi VK, et al. (1998) Interferon alfa-2b alone or in combination with ribavirin as initial treatment for chronic hepatitis C. Hepatitis Interventional Therapy Group. N Engl J Med, 339, 1485-1492.

8.Manns MP, McHutchison JG, Gordon SC, Rustgi VK, Shiffman M, Reindollar R, et al. (2001) Peginterferon alfa-2b in combination with ribavirin comparedto interferon alfa2b plus ribavirin for initial treatment of chronic hepatitis $\mathrm{C}$ : results of a randomized trial. Lancet, 358, 958965.

9.Mchutchison JG, Manns M, Patel K, Poynard T, Lindsay KL, Trepo C, et al. (2002) Adherence to Combination 
Therapy Enhances Sustained Response in Genotype-1-Infected Patients With Chronic Hepatitis C. Gastroenterology, 123, 1061-1069.

10.Hadziyannis SJ, Sette H Jr, Morgan TR, Balan V, Diago M, Marcellin P, et al. (2004) Peginterferon-_2a and ribavirin combination therapy in chronic hepatitis C: a randomized study of treatment duration and ribavirin dose. Ann Intern Med, 140, 346-355.

11.Lindahl K, Stahle L, Bruchfeld A, Schvarcz R. (2005) High-dose ribavirin in combination with standard dose Peginterferon for treatment of patients with chronic hepatitis C. Hepatology, 41, 275-279.

12.European Association for Study of Liver. (2015) EASL Recommendations on Treatment of Hepatitis C 2015. J Hepatol, 63(1), 199-236.

13.Reddy KR, Shiffman ML, Morgan TR, Zeuzem S, Hadziyannis S, Hamzeh FM, et al. (2007) Impact of Ribavirin Dose Reductions in Hepatitis C Virus Genotype 1 Patients Completing Peginterferon Alfa-2a/Ribavirin Treatment. Clin Gastroenterol Hepatol, 5, 124-129.

14.EASL clinical Practice Guidelines: Management of Hepatitis $\mathrm{C}$ virus infection; 2014.

15.Mandell, Douglas, and Benett's Principle and Preactice of infections diseases; seventh edition; volume 2; chapter 154; 2157-2177.

16.Zhu Y, Chen S. (2013) Antiviral treatment of hepatitis $\mathrm{C}$ virus infection and factors affecting efficacy. World $J$ Gastroenterol, 19(47), 8963-73.

17.Hepatology. A clinical Textbook; chapter3, $6,12,16$.

18.García-Samaniego J, Romero M, Granados R, Alemán R, Jorge Juan M, Suárez D, et al. (2013) factors associatel with early virological response to Peginterferon alpha-2a and Ribaverin inchronic Hepatit C. World J Gastroentrol, 19, 1943-1952.
19.Brjalin V, Salupere R, Tallo T, Kuznetsova T, Priimägi L, Tefanova V. (2012) Efficacy of Peginterferon alpha-2a and Ribaverin combiation Therapy in Treatment-Naive Estonium Patients with chronic Hepatit C. Cent Eur J Public Health, 20, 150-155.

20.Kamal S, El Kamary SS, Shardell MD, Hashem M, Ahmed IN, Muhammadi M, et al. (2007) Peginterferon alpha-2b plus Ribaverin in Patients with genotype 4 chronic Hepatitis C. Hepatology, 46, 1732-1740.

21.Zeuzem S, Buti M, Ferenci P, Sperl J, Horsmans Y, Cianciara Y, et al. (2006) Efficacy of 24 weeks treatment with Peginterferon alfa-2b plus ribavirin in patients with chronic hepatitis $\mathrm{C}$ infected with genotype 1 and low pretreatment viremia. J Hepatol, 44, 97103.

22.Berg T, Von Wagner M, Nasser S, Sarrazin C, Heintges T, Gerlach T, et al. (2006) Extended Treatment Duration for Hepatitis C Virus Type 1: Comparing 48 Versus 72 Weeks of Peginterferon-Alfa2a Plus Ribavirin. Gastroenterology, 130, 1086-1097.

23.Bruno S, Camma C, Di Marco V, Rumi M, Vinci M, Camozzi M, et al. (2004) Peginterferon alfa-2b plus ribavirin for naive patients with genotype 1 chronic hepatitis $\mathrm{C}$ : a randomized controlled trial. J Hepatol, 41, 474-481.

24.Arase Y, Kobayashi M, Suzuki F, Suzuki Y, Kawamura Y, Akuta N, et al. (2013) Effect of type 2 diabetes on risk for malignancies includes hepatocellular carcinoma in chronic hepatitis C. Hepatology, 57, 964-973.

25.van der Meer AJ, Veldt BJ, Feld JJ, Wedemeyer H, Dufour JF, Lammert F, et al. (2012) Association between sustained virological response and allcause mortality among patients with chronic hepatitis $\mathrm{C}$ and advanced hepatic fibrosis. JAMA, 308, 25842593. 
26.European Association for the Study of the Liver. (2011) EASL Clinical Practice Guidelines: management of hepatitis C virus infection. J Hepatol, 55, 245-264.

27.Antaki N, Craxi A, Kamal S, Moucari R, Van der Merwe S, Haffar S, et al. (2010) The neglected hepatitis C virus genotypes 4, 5, and 6: an international consensus report. Liver Int, 30, 342355 .

28.Bacon BR, Gordon SC, Lawitz E, Marcellin P, Vierling JM, Zeuzem S, et al. (2011) Boceprevir for previously treated chronic HCV genotype 1 infection. N Engl J Med, 364, 12071217.

29.Jacobson IM, McHutchison JG, Dusheiko G, Di Bisceglie AM, Reddy KR, Bzowej NH, et al. (2011) Telaprevir for previously untreated chronic hepatitis $\mathrm{C}$ virus infection. $N$ Engl J Med, 364, 2405-2416.

30.Poordad F, McCone Jr J, Bacon BR, Bruno S, Manns MP, Sulkowski MS, et al. (2011) Boceprevir for untreated chronic $\mathrm{HCV}$ genotype 1 infection. $N$ Engl $J$ Med, 364, 1195-1206.

31.Zeuzem S, Andreone P, Pol S, Lawitz E, Diago M, Roberts S, et al. (2011) Telaprevir for retreatment of $\mathrm{HCV}$ infection. $N$ Engl J Med, 364, 24172428.

32.Sulkowski MS, Gardiner DF, RodriguezTorres M, Reddy KR, Hassanein T, Jacobson I, et al. (2014) Daclatasvir plus sofosbuvir for previously treated or untreated chronic HCV infection. $N$ Engl J Med, 370, 211-221.
33.Urbanek P, Oltman M, Ivanovski L, Rehák V, Messinger D, Tietz A, et al. (2011) Efficacy and safety of Peginterferon $\alpha$ 2a (40 KD) plus ribavirin in treatmentnaive chronic hepatitis $\mathrm{C}$ patients in Central and Eastern Europe. Eur $J$ Gastroenterol Hepatol, 23(11), 1004-10. 34.Ma P, Yang JM, Hou W, Song SD, Wang L, Lu W. (2013) A preliminary study on the efficacy and influencing factors of interferon for the treatment of genotype 1 chronic hepatitis $\mathrm{C}$ with different dosage forms. Eur $J$ Gastroenterol Hepatol, 25(5), 601-5.

35.Castera L, Sebastiani G, Le Bail B, de Ledinghen V, Couzigou P, Alberti A. (2010) Prospective comparison of two algorithms combining non-invasive methods for staging liver fibrosis in chronic hepatitis C. J Hepatol, 52:, 191198.

36.Castera L, Vergniol J, Foucher J, Le Bail $B$, Chanteloup E, Haaser $M$, et al. (2005) Prospective comparison of transient elastography, Fibrotest, APRI, and liver biopsy for the assessment of fibrosis in chronic hepatitis C. Gastroenterology, 128, 343-350.

37.Chevaliez S, Bouvier-Alias M, Brillet R, Pawlotsky JM. (2009) Hepatitis C virus (HCV) genotype 1 subtype identification in new $\mathrm{HCV}$ drug development and future clinical practice. PLoS One, 4, e8209.

\section{How to cite this article:}

Abolfazl Pourhasan and Neda Zamen Milani. 2016. Evaluation of response to treatment with Ribavirin plus Peginterferon in patients with chronic hepatitis C genotype $1 \mathrm{~b}$. Int.J.Curr.Res.Aca.Rev.4(5): 216-225. doi: http://dx.doi.org/10.20546/ijcrar.2016.405.022 